University of Massachusetts Amherst

ScholarWorks@UMass Amherst

Economics Department Working Paper Series

Economics

2020

\title{
What to Make of the Kaldor-Verdoorn Law?
}

Deepankar Basu

Department of Economics, University of Massachusetts

Manya Budhiraja

Department of Economics, University of Massachusetts

Follow this and additional works at: https://scholarworks.umass.edu/econ_workingpaper

Part of the Economics Commons

\section{Recommended Citation}

Basu, Deepankar and Budhiraja, Manya, "What to Make of the Kaldor-Verdoorn Law?" (2020). UMass Amherst Economics Working Papers. 286.

https://doi.org/10.7275/17572406

This Article is brought to you for free and open access by the Economics at ScholarWorks@UMass Amherst. It has been accepted for inclusion in Economics Department Working Paper Series by an authorized administrator of ScholarWorks@UMass Amherst. For more information, please contact scholarworks@library.umass.edu. 


\title{
What to Make of the Kaldor-Verdoorn Law?
}

\author{
Deepankar Basu* Manya Budhiraja ${ }^{\dagger}$
}

April 26, 2020

\begin{abstract}
The Kaldor-Verdoorn law refers to a positive but less than one-for-one relationship between the growth rates of output and labor productivity, with causality running from the former to the latter. Empirical research has affirmed such a relationship and have found that the Kaldor-Verdoorn coefficient lies between 0 and 1 . But the interpretation of this finding remains unclear. In this paper, we present a model to derive the Kaldor-Verdoorn law. Our results show that the Kaldor-Verdoorn coefficient is jointly determined by the elasticity of factor substitution, labor supply elasticity, the profit share and the increasing returns to scale (or demand-induced technical change) parameter. Hence, estimated Kaldor-Verdoorn coefficients cannot be used, on their own, to infer the presence of aggregate increasing returns to scale - other than in very special cases. We also show that, perhaps surprisingly, an economy without aggregate increasing returns to scale (or without any demand-induced technical progress) can generate a Kaldor-Verdoorn coefficient that lies between 0 and 1.

Keywords: Aggregate productivity, Kaldor-Verdoorn coefficient, labor supply elasticity, CES production function.

JEL Codes: E120; O4.
\end{abstract}

*Department of Economics, University of Massachusetts Amherst, 310 Crotty Hall, 412

N. Pleasant Street, Amherst MA 01002. Email: dbasu@econs.umass.edu

${ }^{\dagger}$ Department of Economics, University of Massachusetts Amherst, 310 Crotty Hall, 412

N. Pleasant Street, Amherst MA 01002. Email: mbudhiraja@umass.edu 


\section{Introduction}

The Kaldor-Verdoorn (KV) law is an important component of heterodox macroeconomic thinking, often understood as capturing either the presence of increasing returns to scales in production or the positive impact of aggregate demand on technological progress (Blecker and Setterfield, 2019; Foley et al., 2019). The idea behind this law was first presented by Verdoorn (1949) and later highlighted by Kaldor (1966). In its simplest form, the KV law is the existence of a positive relationship between the growth rate of labor productivity and the growth rate of output in the industrial sector, with causality running from the latter to the former. In empirical work, the law is often captured by a regression of the following form,

$$
p=a_{0}+a_{1} q+u
$$

where $p$ and $q$ refer to the growth rates, respectively, of labor productivity and output in the industrial sector, $u$ is a stochastic error term, and $a_{1}$ is the Kaldor-Verdoorn coefficient.

The intuitive appeal of the KV law rests on the KV coefficient being positive and less than unity, i.e. $0<a_{1}<1$. For, if $a_{1}$ is positive and less than unity then two important conclusions would follow. First, the growth rate of output would have a positive impact on the growth rate of labor productivity (because $a_{1}>0$ ), i.e. demand growth (captured by the growth rate of output) would have a positive impact on technological change (measured by the growth rate of labor productivity). Second, and probably more importantly, the impact of output growth would be less than one-forone on labor productivity growth (because $a_{1}<1$ ). This would mean that the growth rate of labor productivity is accompanied by a positive growth rate of employment, i.e. productivity growth in the industrial sector would go hand in hand with labor absorption from the less productive sectors of the economy (e.g. agriculture). This is the key reason for Kaldor's emphasis on structural change as being an integral part of economic growth in less developed economies (Ros, 2013; Blecker and Setterfield, 2019).

Following Kaldor's pioneering contribution, a large literature in heterodox macroeconomics has studied and used the KV law (Fingleton and McCombie, 1998; Leon-Ledesma, 1999; Storm and Naastepad, 2012; Ros, 2013; Foley et al., 2019). Many studies have found that the estimate of $a_{1}$ is indeed positive and less than unity (Kaldor, 1966; Fingleton and McCombie, 1998; Ros, 
2013). An important strand of literature has investigated ways to consistently estimate the KV coefficient - by dealing with possible sources of bias like omitted variable and bidirectional causality (Thirlwall, 1983; Bairam, 1987; Fingleton and McCombie, 1998; Leon-Ledesma, 1999). In this paper, our concern is not with the empirical side of discussions. Rather our focus is on the theoretical underpinning of the law.

Even when there are proper econometric methods to consistently estimate the KV coefficient, the question about its interpretation will still remain to be addressed. A reading of the extant literature suggests that there is less clarity about how to interpret the KV coefficient than on how to estimate it consistently. The lack of clarity is natural because the relationship captured by the Verdoorn law is a reduced-form relationship - in the sense that the KV coefficient is a function of underlying parameters coming from the production side of the economy and from labor market behaviour. Proper interpretation of the KV coefficient (in the regression that captures the KV law) requires the explicit use of a theoretical framework.

Proponents of a demand-led interpretation of economic growth in capitalist economies use an implicit theoretical framework which leads them to interpret the Verdoorn coefficient as reflecting the presence of increasing returns to scale or demand-induced technical progress in the industrial sector (Kaldor, 1966; Leon-Ledesma, 1999; Storm and Naastepad, 2012). In fact, scholars adhering to such an approach use the estimated value of $a_{1}$ - the fact that $a_{1}$ is positive and less then unity - to implicitly infer the presence of increasing returns to scale or demand-induced technical progress. ${ }^{1}$

This methodology suffers from two serious problems - both related to the underlying theory. First, the theoretical relationship that can be used to unambiguously infer the presence of increasing returns to scale or demandinduced technical progress from estimated values of the $\mathrm{KV}$ coefficient is only valid when an economy is on its steady state growth path (Vries, 1980; Bairam, 1987). Second, the methodology is also partly misleading because the underlying theory is incomplete. The theoretical analysis ignores the role of the labor market, especially the labor supply elasticity with respect to the wage rate, in determining the KV coefficient (Rowthorn, 1979; Bairam, 1987; Ros, 2013).

In this paper, we will follow and extend the analysis in Ros $(2000,2013)$

\footnotetext{
${ }^{1}$ On the other hand, scholars using a neoclassical framework report finding evidence in favour of constant returns to scale Basu and Fernald (1997).
} 
in an attempt to understand the theoretical structure that underlies the Kaldor-Verdoorn law. By bringing together analyses of the production side of the economy and the labor market, one is able to derive an explicit expression for the KV coefficient. Such an analysis offers two important insights for heterodox macroeconomics. First, we see clearly that, in general, the $\mathrm{KV}$ coefficient is determined by a combination of the increasing returns to scale (or demand-induced technical change) parameter, the elasticity of factor substitution, the profit share and the elasticity of labor substitution. An immediate conclusion follows: in general, the KV coefficient cannot be interpreted as providing unambiguous information about the increasing returns to scale (or demand-induced technical change) parameter. Second, we see that only under rather strong assumptions can the KV coefficient allow us to make direct inferences about the increasing returns to scale (or demandinduced technical progress) parameter. Both these points suggest caution in using and interpreting the $\mathrm{KV}$ law or the $\mathrm{KV}$ coefficient within heterodox macroeconomic models.

The rest of the paper is organized as follows: in section 2, we discuss the production side of the economy; in section 3, we discuss the steady state analysis of the model of production that is often used to motivate the $\mathrm{KV}$ coefficient and point to its limitations; in section 4, we discuss the labor market side of the economy; in section 5, we bring together the analyses of production and labor market to derive expressions for the $\mathrm{KV}$ coefficient in a more general setting; in section 6 , we discuss some interesting special cases; in section 7 , we present a simple empirical example; and finally, in section 8, we conclude. we will use the following notation: $B, Q, K, E, W, P$ will denote technology, output, capital stock, employment, wages and labor productivity in the industrial sector, where $P=Q / E$; and, lowercase letters, $q, k, e, w, p$, will denote growth rates of the corresponding variables. For instance, $q=(1 / Q)(d Q / d t)$, and so on.

\section{Production and Technology}

\subsection{The Production Function}

We will capture the production conditions in the industrial sector with a constant elasticity of substitution (CES) production function (Arrow et al., 
1961),

$$
Q=B\left[a K^{\psi}+(1-a) E^{\psi}\right]^{\frac{1}{\psi}},
$$

where $Q, K, E$ denote output, capital and labor, respectively, the parameter $a$ is positive, i.e. $a>0, B$ denotes technology (which we will specify below in two alternative ways), and the elasticity of substitution between labor and capital is given by $\sigma=1 /(1-\psi)$, where $\sigma \geq 0$.

The advantage of using a CES production function is its generality. Commonly specified functional forms are special cases of the CES production function. For instance, the Cobb-Douglas production function, which is used widely in the neoclassical tradition, is a special case of the CES production function with the elasticity of substitution being unity, i.e. $\sigma=1$. Again, the fixed-coefficient production function (Leontief production function), which is used widely in heterodox macroeconomics, is a special case of the CES production function with zero elasticity of substitution, i.e. $\sigma=0$. Thus, once we derive results for the CES specification, we will be easily able to generate results for these special cases.

Dividing both sides of (2) by $E$, we get

$$
P=B\left[a C^{\psi}+(1-a)\right]^{\frac{1}{\psi}}
$$

where $C=K / E$ denotes capital intensity. Taking the logarithm and then the derivative with respect to time on both sides, we get,

$$
p=b+\left[\frac{a C^{\psi}}{a C^{\psi}+(1-a)}\right] c
$$

where $b=(1 / B)(d B / d t)$ denotes the growth of the aggregate technology parameter, and $c=(1 / C)(d C / d t)$, is the growth rate of capital intensity. Since $c=k-e$, we have,

$$
p=b+\left[\frac{a C^{\psi}}{a C^{\psi}+(1-a)}\right](k-e) .
$$

Using the expression for the profit share with a CES production function,

$$
\pi \equiv \frac{K}{Q} \frac{\partial Q}{\partial K}=\frac{a C^{\psi}}{a C^{\psi}+(1-a)},
$$

the above becomes,

$$
p=b+\pi(k-e),
$$


which gives us the relationship between the growth rates of labor productivity, the capital stock, the profit share and employment coming out of the technological constraints of the economy (and we have $0 \leq \pi \leq 1$ ). To complete the description of the production side of the industrial sector, we need to specify technology. In this paper, we will discuss two different specifications of technology, both of which are meant to capture the existence of scale effects.

\subsection{Rosenstein-Rodan Technology}

One way to specify the technological possibilities in the industrial sector is to allow for technological economies of scale external to the firm (Ros, 2013). This conception of technology was common in the early development economics literature pioneered by P. Rosenstein-Rodan, R. Nurske, G. Myrdal, T. Scitovsky, among others (Rosenstein-Rodan, 1943; Scitovsky, 1954). We can capture this conception of technology by specifying the technology parameter in (2) to be an increasing function of the economy-wide average size of the capital stock, $B=\tilde{K}^{\mu}$ where $\tilde{K}$ denotes the average capital stock in the industry and $\mu \geq 0$ captures the increasing returns to scale generated by technological external economies. In equilibrium, all firms in the indus-

trial sector will have the industry-average capital stock, i.e. $\tilde{K}=K$, so that $B=K^{\mu}$. Hence we have $b=\mu k$. Using this relationship and the fact that $q=p+e,(6)$ becomes

$$
p=(\mu+\pi) k-\pi e .
$$

\subsection{Kaldor Technology}

An alternative way to specify the technological possibilities in the industrial sector is to use Kaldor's insights about demand-led technical change (Fingleton and McCombie, 1998; Storm and Naastepad, 2012; Blecker and Setterfield, 2019). The intuition behind this relationship can be traced back through Allyn Young to Adam Smith (Blitch, 1983). It asserts that the size of the market, a proxy for aggregate demand, has a positive impact on technological change. It is often noted that this positive impact reflects the existence of 'dynamic' increasing returns to scale and can arise from such factors as learning by doing, $\mathrm{R} \& \mathrm{D}$ expenditures, the lumpy nature of investments (Blecker and Setterfield, 2019, pp. 384-385). 
In this specification of technological possibilities, we will have $b=\xi q$, with $\xi \geq 0$ capturing the effect of demand-induced technical change - so that the growth rate of the technology parameter, $b$, is positively impacted by the growth rate of output, $q$. Using this relationship and the fact that $q=p+e$, (6) becomes

$$
p=\left(\frac{\pi}{1-\xi}\right) k-\left(\frac{\pi-\xi}{1-\xi}\right) e .
$$

To complete the analysis, we will have to look at the labor market. But before we do so, let us quickly note a special, and restrictive, case that has been extensively used as a way to characterize the KV law: steady state analysis.

\section{$3 \quad$ Steady State Analysis}

If the economy is on a steady state growth path, then the capital-output ratio is constant. Hence, $q=k$. We can use this to derive a relationship between the growth rates of productivity and output.

If technology has increasing returns to scale coming from external economies, then (7) characterises production. Using (7), $q=k$ and replacing $e$ with $q-p$, we get, on rearranging terms,

$$
p=\left(\frac{\mu}{1-\pi}\right) q .
$$

On the other hand, if technological progress is demand-drive, then (8) characterises production. Using (8), $q=k$ and replacing $e$ with $q-p$, we get, on rearranging terms,

$$
p=\left(\frac{\xi}{1-\pi}\right) q .
$$

If we make the further assumption that the production function is CobbDouglas, so that the profit share is constant and given $\pi=a$, then we get, in the case of technological externalities,

$$
p=\left(\frac{\mu}{1-a}\right) q
$$


and in the case of demand-driven technical progress, we have,

$$
p=\left(\frac{\xi}{1-a}\right) q .
$$

The important point is that in both cases, the KV coefficient, $a_{1}=d p / d q$, is determined completely by conditions of production. In the the case of technological externalities, it is given by $a_{1}=\mu /(1-a)$ and in the case of demand-driven technical progress, it is given by $a_{1}=\xi /(1-a)$. Thus, in both cases, the Verdoorn coefficient is positive and less than unity if $\mu>0$ or $\xi>0$ (increasing returns to scale) and $a+\mu<1$ or $a+\xi<1$ (diminishing returns to capital). This special case seems to have been most extensively used as a characterization of Verdoorn's law (Fingleton and McCombie, 1998; Leon-Ledesma, 1999).

But the twin assumptions of Cobb-Douglas technology and steady state analysis make the approach rather restrictive. The key intuitive problem with this steady state analysis, apart from the use of Cobb-Douglas technology, is that it ignores the impact of capital deepening on labor productivity growth - a phenomenon that is bound to be important when the economy has not yet reached its steady state. Hence, we must abandon this restrictive approach and move to a more general analysis, as argued by Ros $(2000,2013)$.

\section{Labor Market}

Let us begin by looking at labor demand arising from the behaviour of capitalist firms. Profit-maximising capitalist firms choose the level of labor by equating the real wage rate, $W$, to the marginal product of labor, $\partial Q / \partial E$, i.e.

$$
W=(1-a) B\left[a C^{\psi}+(1-a)\right]^{\frac{1-\psi}{\psi}},
$$

where we have used the production function in (2). Taking the logarithm and then the derivative with respect to time gives us

$$
w=b+(1-\psi)\left[\frac{a C^{\psi}}{a C^{\psi}+(1-a)}\right] \frac{1}{C} \frac{d C}{d t}
$$

which becomes

$$
w=b+\frac{\pi}{\sigma}(k-e)
$$


where we have used (5), the fact that $\sigma=1 /(1-\psi)$ is the elasticity of factor substitution in the CES production function in (2), and the relationship, $c=k-e$.

\subsection{Rosenstein-Rodan Technology}

When the technology is of the Rosenstein-Rodan type, we have $b=\mu k$. Using this in (11), a little algebraic manipulation gives

$$
e=\left(1+\frac{\mu \sigma}{\pi}\right) k-\frac{\sigma}{\pi} w
$$

On the supply side of the labor market, let us assume a constant elasticity of labor supply. Let $\eta$ denote the elasticity of labor supply with respect to the real wage, i.e. $E=A W^{\eta}$, where $A$ is some constant and $\eta \geq 0$. Hence, on taking logarithms and then the derivative with respect to time gives us

$$
e=\eta w
$$

Thus, the growth rate of the supply of employment is a constant multiple of the growth rate of the real wage rate, as would be expected in a constant elasticity labor supply function.

When the labor market is in equilibrium, the growth rate of labor supply given by (13) will be equal to the growth rate of labor demand given by (12). Using (13) to substitute for $w$ in (12), we get

$$
e=\left(1+\frac{\mu \sigma}{\pi}\right) k-\frac{\sigma}{\pi} \frac{e}{\eta}
$$

A little algebraic manipulation gives us the following characterization of labor market equilibrium:

$$
e=\left[\frac{\pi+\mu \sigma}{\pi+(\sigma / \eta)}\right] k
$$

Here we have the relationship between the growth rate of employment and the growth rate of the capital stock that is consistent with labor market equilibrium when technology is characterized by external economies (of the Rosenstein-Rodan variety). 


\subsection{Kaldor Technology}

When technology is of the Kaldor variety, i.e. technical progress is demanddriven, we have $b=\xi q$. Using this in (11), we get

$$
w=\xi q+\frac{\pi}{\sigma}(k-e)
$$

which, combined with the labor supply condition, $e=\eta w$, gives

$$
\left(\frac{1}{\eta}+\frac{\pi}{\sigma}\right) e=\xi q+\frac{\pi}{\sigma} k
$$

Here we have the relationship between the growth rate of employment and the growth rate of the capital stock that is consistent with labor market equilibrium when technology is characterized by demand-driven technical change (of the Kaldorian variety).

\section{$5 \quad$ Bringing it All Together}

We are now ready to derive expressions for the KV coefficient by bringing together the characterization of production and the labor market equilibrium.

\subsection{Rosenstein-Rodan Technology}

Using the labor market equilibrium condition (14) and the technological constraints captured by (7), we get

$$
p=\left[\frac{\mu \pi(1-\sigma)+(\sigma / \eta)(\pi+\mu)}{\pi+\mu \sigma}\right] e
$$

and further using the fact that $e=q-p$, we get

$$
p=\left[\frac{\mu \pi(1-\sigma)+(\sigma / \eta)(\pi+\mu)}{\pi+\mu \sigma}\right](q-p),
$$

which can be rearranged to give

$$
p=\left[\frac{\mu \pi(1-\sigma)+(\sigma / \eta)(\pi+\mu)}{\pi+\mu \sigma+\mu \pi(1-\sigma)+(\sigma / \eta)(\pi+\mu)}\right] q .
$$


This shows that the KV coefficient, $a_{1}=d p / d q$, is given by

$$
a_{1}=\frac{\mu \pi(1-\sigma)+(\sigma / \eta)(\pi+\mu)}{\pi+\mu \sigma+\mu \pi(1-\sigma)+(\sigma / \eta)(\pi+\mu)},
$$

which is the same expression as in Ros (2013, pp. 198-201).

The value of the KV coefficient always lies within the $(0,1)$ open interval. We state this as

Proposition 1. If all parameters appearing in (16) are positive fractions then the $K V$ coefficient, $a_{1}$, is positive and less than unity.

\subsection{Kaldor Technology}

Using the labor market equilibrium condition (15) and the technological constraints captured by (8), we get

$$
\left(\frac{1}{\eta}+\frac{\xi}{\sigma}\right) e=\left(\frac{1-\xi}{\sigma}\right) p+\xi q
$$

which, on using the fact that $e=q-p$, becomes, on rearrangement,

$$
p=\left[\frac{\sigma+\xi \eta(1-\sigma)}{\eta+\sigma}\right] q .
$$

This shows that the KV coefficient, $a_{1}=d p / d q$, is given by

$$
a_{1}=\frac{\sigma+\xi \eta(1-\sigma)}{\eta+\sigma} .
$$

Since all parameters appearing in (17) are positive, we can easily see that if $\sigma<\eta \xi /(\eta \xi-1)$ then the KV coefficient is positive, and if $\xi(1-\sigma)<1$, then it is less than unity. Bringing these together, we get

Proposition 2. If all parameters appearing in (17) are positive fractions, $\eta>(1 / \xi)-1$ and

$$
1-\frac{1}{\xi}<\sigma<\frac{\eta \xi}{\eta \xi-1},
$$

then the $K V$ coefficient is positive and less than unity.

The condition, $\eta>(1 / \xi)-1$ ensures that the upper bound is larger than the lower bound in (18), which, in turn, ensures that the KV coefficient is positive and less than unity. The result in this proposition shows that as long as the elasticity of factor substitution is neither too large nor too small, the KV coefficient will lie in the open interval $(0,1)$. 


\subsection{Summary of Results}

In this section, we have demonstrated two important results about the KV coefficient. First, the expressions in (16) and (17) show that the KV coefficient is determined jointly by parameters capturing the elasticity of factor substitution, the labor supply elasticity, the profit share and the increasing returns to scale parameter (in case of 16) and the technical progress parameter (in case of 17). Thus, in general, the KV coefficient cannot be identified solely with either increasing returns to scale effects or demand-driven technical progress effects. ${ }^{2}$

Second, not only is the KV coefficient determined jointly by parameters capturing the elasticity of factor substitution, the labor supply elasticity, the profit share and the increasing returns to scale parameter (or the technical progress parameter), but there are important restrictions that need to be placed on the relative magnitudes of these parameters for the KV coefficient to attain values in the $(0,1)$ open interval when we use a Kaldorian technology specification. These conditions are specified in Proposition 2. As far as we can see, there are no intuitive explanations for these parameter restrictions. But these do highlight the fact that, in general, i.e. without these parameter restrictions, the $\mathrm{KV}$ coefficient will not lie in the meaningful range between 0 and 1 when we use a demand-induced technical progress framework.

\section{Special Cases}

There are many interesting special cases in which the KV coefficient attains a more simplified expression, and we now turn to consider some of them. In each case, we discuss results for the increasing returns technology (Rosenstein-Rodan) and demand-driven technical progress (Kaldor) in that order.

\footnotetext{
${ }^{2}$ In the Appendix to Chapter 3, Storm and Naastepad (2012) also derive an expression for the KV coefficient. The expressions of the KV coefficient derived in this paper are different from the one in Storm and Naastepad (2012) because of different assumptions about the evolution of what we have called the technology parameter, i.e. $B$ in (2). More importantly, Storm and Naastepad (2012) do not comment on the fact that the KV coefficient is determined by factors other than those capturing increasing returns to scale.
} 


\subsection{Cobb-Douglas Production Function}

If the elasticity of factor substitution is unity, i.e. the manufacturing sector has a Cobb-Douglas production function, then we have, on substituting $\sigma=1$ in (16),

$$
a_{1}=\frac{1}{1+\eta}
$$

and on substituting $\sigma=1$ in (17), we get the same expression,

$$
a_{1}=\frac{1}{1+\eta}
$$

Thus, in this case, the KV coefficient is completely determined by the labor supply elasticity. It is not impacted by the increasing returns parameter, $\mu$, or technical progress parameter, $\xi$. This is intuitive. With a Cobb-Douglas production function, the profit share is constant. Thus the impact of any change in output growth on productivity growth will be completely mediated by the response of labor supply.

\subsection{Leontief Production Function}

If the elasticity of factor substitution is zero, i.e. the industrial sector has a Leontief production function, then we have, on substituting $\sigma=0$ in (16),

$$
a_{1}=\frac{\mu}{1+\mu}
$$

and on substituting $\sigma=0$ in (17), we get

$$
a_{1}=\xi
$$

Thus, in this case, the KV coefficient is completely determined by technology - the increasing returns parameter, $\mu$ in the Rosenstein-Rodan technology, and the technical progress parameter, $\xi$, in the case of the demand-driven technical change specification (Kaldor technology). In either specification, the labor supply elasticity has no impact on its magnitude. This is intuitive: with a fixed coefficient technology, changes in the elasticity of labor supply has no impact on the choice of capital intensity. 


\subsection{Labor Constrained Economy}

If the economy is completely constrained by the supply of labor, then the elasticity of labor supply is zero. To compute the KV coefficient in this case, first multiply the numerator and denominator in (16) by $\eta$ and then take the limit as $\eta \rightarrow 0$. Using this method, we get

$$
a_{1}=\frac{\sigma(\pi+\mu)}{\sigma(\pi+\mu)}=1 .
$$

On the other hand, taking limit as $\eta \rightarrow 0$ in (17), we get the same result,

$$
a_{1}=\frac{\sigma}{\sigma}=1
$$

In this case, the KV coefficient is unity because labor supply cannot change. So, the increase in the growth rate of output leads to a one-for-one change in the growth rate of productivity. There is no impact on employment because labor supply is fixed.

\subsection{Labor Surplus Economy}

If the economy has surplus labor in the Lewisian sense, then the elasticity of labor supply is infinite. Hence, taking the limit of the expression in (16) as $\eta \rightarrow \infty$, we get

$$
a_{1}=\frac{\mu \pi(1-\sigma)}{\pi+\mu \sigma+\mu \pi(1-\sigma)}=\frac{1}{1+\frac{\pi+\mu \sigma}{\mu \pi(1-\sigma)}} .
$$

and taking the limit of the expression in (17) as $\eta \rightarrow \infty$, we get

$$
a_{1}=\xi(1-\sigma)
$$

This special case is of interest to development economists. It shows that in a labor surplus economy, the $\mathrm{KV}$ coefficient is, in general, determined by the elasticity of factor substitution $(\sigma)$, the profit share $(\pi)$, and returns to scale parameter with Rosenstein-Rodan technology $(\mu)$ or the demand-driven effect on technical progress with Kaldor technology $(\xi)$.

This special case also highlights an important restriction that the elasticity of factor substitution must satisfy. If we use Rosenstein-Rodan technology

discussed in section 2.2 to characterize the modern sector in a labor surplus 
economy, then they we are faced with the following possibility: if $\sigma>1$, then the KV coefficient will be larger than unity. On the other hand, if we choose to use Kaldor technology discussed in section 2.3, we face the following possibility: if $\sigma>1$, then the KV coefficient will be negative. ${ }^{3}$

Both scenarios are perverse from the perspective of economic development. The first scenario implies that in a labor surplus economy, the KV effect will mean a more than one-for-one effect of output growth on productivity growth, leading to a negative employment growth. Thus output growth will undermine the reallocation of labor from the low to the high productivity sector. This suggests that a demand-led productivity regime in a labor surplus economy is inimical to structural change and economic growth if $\sigma>1$.

The second scenario implies the exact opposite: output growth will lead to a fall in the growth of productivity in the industrial sector. While this means that employment growth will be positive, the positive effect will be tempered by the fact that labor is getting reallocated to a sector with falling productivity if $\sigma>1$. To rule out both these perverse scenarios, it will be essential for the elasticity of factor substitution to be less than unity. Hence, on pure theoretical grounds, a Cobb-Douglas production function seems to be ruled out as a good characterization of technology in a labor surplus economy undergoing structural change.

\subsection{Absence of Scale Effects}

What is the magnitude of the KV coefficient if the production technology displays constant returns to scale or does not display any demand-induced technical progress? In the framework set up in this note, constant returns to scale technology can be captured by assuming that $\mu \rightarrow 0$. Using $\mu \rightarrow 0$ in (16), we see that the KV coefficient is given by

$$
a_{1}=\frac{1}{1+\frac{\eta}{\sigma}} .
$$

In a similar manner, the absence of a demand-induced technical progress effect can be captured with the condition that $\xi \rightarrow 0$. Using this in (17), we

\footnotetext{
${ }^{3}$ If we re-write the condition in (18) and evaluate it with $\eta \rightarrow \infty$, we get $\sigma<1$. Thus, when $\sigma>1$, we are violating the condition in (18). That is why we are getting a KV coefficient that lies outside the $(0,1)$ interval.
} 
see that the KV coefficient is given by

$$
a_{1}=\frac{1}{1+\frac{\eta}{\sigma}}
$$

The results in (27) and (28) would seem to raise serious doubts on the approach of identifying the KV coefficient either with the increasing returns to scale parameter or with the impact of demand on technical progress (Kaldor, 1966; Leon-Ledesma, 1999; Storm and Naastepad, 2012). Since $\sigma>0$ and $\eta>0$ (and finite), we have, with constant returns to scale technology, the KV coefficient in (27) being positive and less than unity. Similarly, since $\eta>0$ and $\sigma>0$, the KV coefficient in (28) is positive and less than unity even in the absence of any demand-induced effect on technical progress. Thus, under plausible assumptions about distribution, factor substitution elasticity and labor supply elasticity, the KV coefficient can be positive and less than unity even with constant returns to scale and even when there is no demand-induced technical progress. This would seem to undermine any approach that only uses estimated values of the KV coefficient to draw conclusions about the existence of increasing returns to scale or demand-induced technical progress effects.

\section{An Empirical Example}

Let us now turn to a positive question: how can we make valid inference about the increasing returns to scale (or demand-induced technical progress) parameter? The expressions in (16) and (17) suggest answers. Let us illustrate this with (16): if we could consistently estimate $a_{1}, \sigma, \pi$ and $\eta$, then the expression in (16) can be used to form a consistent estimate of $\mu$.

Existing studies show that the KV coefficient is about 0.5 , i.e. $\hat{a}_{1}=1 / 2$ (Foley et al., 2019). Using a meta-analysis of 41 studies published between 1961 and 2016, Knoblauch et al. (2020) find that the elasticity of substitution between labor and capital lie in the range of 0.6 and 0.7 .4 Hence, we can use

\footnotetext{
${ }^{4}$ While all studies reject the Cobb-Douglas production function $(\sigma=1)$, there is very little evidence for the Leontief production function $(\sigma=0)$ as well. Moreover, since the estimate of the elasticity of factor substitution is less than unity, the KV coefficient for a labor surplus economy given in (25) is smaller than unity. This is reassuring and suggests that a KV-type effect, if it exists, will not lead to perverse results in labor surplus economies (as highlighted in the special case of infinite labor supply elasticity).
} 
$\hat{\sigma}=2 / 3$. Using data from the U.S. Bureau of Economic Analysis (BEA), we define the profit share as the ratio of net operating surplus and net value added. Our calculations show that the average profit share in the US is about 20 percent for both the corporate business sector and the nonfinancial corporate business sector for the period 1946-2018. Hence, we can use $\hat{\pi}=$ $1 / 5$.

Using these parameter values in (16), we get the following relationship between the labor supply elasticity, $\eta$ and the increasing returns parameter, $\mu$

$$
\mu=\frac{2-3 \eta}{9 \eta-10},
$$

so that an estimate of $\eta$ will help us in pinning down $\mu$. But even without estimating $\eta$, we can see that increasing returns to scale will only arise, i.e. $\mu>0$, if $2 / 3<\eta<10 / 9$. If $\eta$ lies outside this range then we will be able to rule out the presence of increasing returns to scale. A recent survey of existing estimates of labor supply elasticity suggests that its value is about 0.4, i.e. $\hat{\eta}=0.4$ (Reichling, 2012). Thus, $\eta$ falls below the lower bound of the region we identified for the presence of increasing returns to scale: $2 / 3$. This would suggest, as a tentative finding, that increasing returns to scale does not characterize industrial production in the US.

\section{Conclusion}

Nicholas Kaldor's insightful writings on economic growth placed lot of importance on a positive relationship between output growth and labor productivity growth (Kaldor, 1966). The idea originated in previous work by Verdoorn (1949) and, since Kaldor's use of it in his own writings, has come to occupy an important place in heterodox macroeconomic thinking in the form of the Kaldor-Verdoorn law. The most common form of the KV law is a regression relationship between the growth rate of labor productivity (dependent variable) and the growth rate of output in the industrial sector (independent variable). The coefficient on the growth rate of output is the $\mathrm{KV}$ coefficient and much of the literature posits it to be positive but less than unity. While many studies, including Kaldor's, have found the KV coefficient to lie between 0 and 1 , it is not immediately clear how to interpret such a finding.

The difficulty of interpreting the KV coefficient comes partly from the 
absence of an elaborated theory that could justify it. In this paper, we have extended the analysis in Ros (2013) and derived explicit expressions for the KV coefficient using a model with a CES production function with aggregate increasing returns to scale à la Rosenstein-Rodan (or demand-driven technical progress à la Kaldor) and an explicit labour market. We find that the KV coefficient is jointly determined by many parameters, including those related to labor supply elasticity, elasticity of factor substitution, the profit share and aggregate increasing returns to scale. This means that the KV coefficient, on its own, cannot be used to infer the presence of increasing returns to scale - the key intuition behind the KV law. Most of the existing literature that considers the KV coefficient as informative of aggregate increasing returns has avoided the problem raised in this paper by imposing restrictive assumptions - like steady state analysis or Cobb-Douglas production functions. In the absence of these restrictive assumptions, the KV coefficient cannot be informative, on its own, about aggregate increasing returns to scale à la Rosenstein-Rodan (or demand-driven technical progress à la Kaldor).

After deriving expressions for the KV coefficient in a general setting, we have also looked at special cases. One special case that is worth highlighting relates to an economy without aggregate increasing returns to scale à la Rosenstein-Rodan (or an economy with an absence of demand-driven technical progress à la Kaldor). If a researcher were to estimate a KV-type regression in such an economy, she would find that the KV coefficient is positive and less than unity. She would then conclude that the economy exhibits the presence of aggregate increasing returns to scale even though it is absent by construction! The results in this paper, therefore, urge caution in using a reduced-form relationship like a KV law to make inferences about important structural features of the economy like aggregate increasing returns to scale.

\section{References}

Arrow, K. J., Chenery, H. B., Minhas, B. S., and Solow, R. M. (1961). Capital-labor substitution and economic efficiency. The Review of Economics and Statistics, 43(3):225-250.

Bairam, E. I. (1987). The verdoorn law, returns to scale and industrial growth: A review of the literature. Australian Economic Papers, 26(48):20-42. 
Basu, S. and Fernald, J. G. (1997). Returns to scale in us production: Estimates and implications. Journal of Political Economy, 105:249-283.

Blecker, R. A. and Setterfield, M. (2019). Heterodox Macroeconomics: Models of Demand, Distribution and Growth. Edward Elgar, Cheltenham, UK.

Blitch, C. P. (1983). Allyn young on increasing returns. Journal of Post Keynesian Economics, 5(3):359-372.

Fingleton, B. and McCombie, J. S. L. (1998). Increasing returns and economic growth: Some evidence for manufacturing from the european union regions. Oxford Economic Papers, 50:89-105.

Foley, D. K., Michl, T. R., and Tavani, D. (2019). Growth and Distribution. Second edition. Harvard University Press, Cambridge, MA.

Kaldor, N. (1966). Causes of the Slow Rate of Economic Growth of the UK. An Inaugural Lecture. Cambridge University Press, Cambridge, UK.

Knoblauch, M., Roessler, M., and Zwerschke, P. (2020). The elasticity of substitution between capital and labour in the us economy: A metaregression analysis. Oxford Bulletin of Economics and Statistics, 82(1):62-82.

Leon-Ledesma, M. (1999). Verdoorn's law and increasing returns: An empirical analysis of the Spanish regions. Applied Economics Letters, 6:373-376.

Reichling, F. (2012). Review of estimates of the frisch elasticity of labor supply. Working Paper 2012-13, Congressional Budget Office, Washington D.C.

Ros, J. (2000). Development Theory and the Economics of Growth. University of Michigan Press, Ann Arbor, MI.

Ros, J. (2013). Rethinking Economic Development, Growth and Institutions. Oxford University Press, New York, NY.

Rosenstein-Rodan, P. (1943). Problems of industrialization in eastern and south eastern europe. Economic Journal, 53:202-211.

Rowthorn, R. E. (1979). A note on verdoorn's law. Economic Journal, 89:131-133. 
Scitovsky, T. (1954). Two concepts of external economies. Journal of Political Economy, 62(2):143-151.

Storm, S. and Naastepad, C. W. M. (2012). Macroeconomics Beyond the NAIRU. Harvard University Press, Cambridge, MA.

Thirlwall, A. P. (1983). A plain man's guide to kaldor's growth laws. Journal of Post Keynesian Economics, 5(3):345-358.

Verdoorn, P. J. (1949). Fattori che regolano la sviluppo della produttivita del lavoro. L'Industria, 1:3-10. English translation by A. P. Thirlwal and G. Thirlwal (1979) in Research in Population and Economics.

Vries, A. W. D. (1980). The verdoorn law revisited: A note. European Economic Review, 14(2):271-277. 


\section{Appendix}

\section{Proof of Proposition 1.}

To derive the conditions for ensuring that $a_{1}>0$, note that the denominator in (16) is always positive. For the denominator to be negative, we would need to have $\pi+\mu \pi+\sigma[\mu(1-\pi)+(\pi / \eta)+(\mu / \eta)]<0$, which is not possible because $0 \leq \pi \leq 1$, and all other parameters are positive. Hence, for $a_{1}$ to be positive, we only need the numerator in (16) to be positive. This is ensured if $\sigma>\eta \mu \pi /(\eta \mu \pi-\pi-\mu)$. And this condition is satisfied if all parameters are positive fractions, because, in that case $\eta \mu \pi-\pi-\mu<0$, so that $\eta \mu \pi /(\eta \mu \pi-\pi-\mu)<0$. Since $\sigma \geq 0$, we have $\sigma \geq 0>\eta \mu \pi /(\eta \mu \pi-\pi-\mu)$.

To derive conditions to ensure that $a_{1}<1$, note that we only need to ensure $\pi+\sigma \mu>0$ (so that the denominator is greater than the numerator in equation 16). But this is immediately satisfied because $\sigma \geq 0>-(\pi / \mu)$.

\section{Proof of Proposition 2.}

To derive the conditions for $a_{1}$ in (17) to be positive, note that the denominator in (17) is always positive. Hence we only need the numerator to be positive, i.e. $\sigma+\xi \eta(1-\sigma)>0$. This will be ensured if $\sigma<\xi \eta /(\xi \eta-1)$, and $\xi$ and $\eta$ are positive fractions - which is the upper bound in (18).

To derive the conditions to ensure that $a_{1}$ in (17) is less than unity, we need the numerator to be less than the denominator, i.e. $\sigma+\xi \eta-\xi \eta \sigma<\eta+\sigma$. This will be ensured if $\sigma>1-(1 / \xi)$ - which is the lower bound in (18). As long as $\eta>(1 / \xi)-1$, both conditions in (18) can be satisfied and we will have $0<a_{1}<1$. 